\title{
Isolation and identification of chromium-tolerant bacterial strains and their potential to promote plant growth
}

\author{
Muhammad Arshad ${ }^{1, *}$, Anza Javaid ${ }^{1}$, Maria Manzoor ${ }^{1}$, Kiran Hina $^{2}$, Muhammad Arif Ali ${ }^{3}$, and Iftikhar Ahmed ${ }^{4}$ \\ ${ }^{1}$ Institute of Environmental Sciences and Engineering, School of Civil and Environmental Engineering, National University of Science \\ and Technology, H-12, Islamabad 44000, Pakistan \\ ${ }^{2}$ Department of Environmental Sciences, Hafiz Hayat Campus, University of Gujrat, Gujrat, 54000, Pakistan \\ ${ }^{3}$ Department of Soil Science, Faculty of Agricultural Sciences \& Technology, Bahauddin Zakariya University, Multan, 60800, Pakistan \\ ${ }^{4}$ Institute of Microbial Cultural Collection of Pakistan (IMCCP), National Agricultural Research Centre (NARC), Park Road, Islamabad, \\ 45500, Pakistan
}

\begin{abstract}
Remediation and management of Chromium $(\mathrm{Cr})$ contaminated soils for safe usage has been a serious challenge. The aim of present work was to isolate and identify $\mathrm{Cr}$ tolerant bacterial strains and assessing their plant growth promoting potential under controlled conditions. Soil samples were collected from Gujrat District, Pakistan, and analyzed for Cr content and bacteria isolation. In-vitro screening was done for chromium tolerance and plant growth-promoting (PGP) abilities. The tolerant isolates which also exhibited PGP abilities were used as inoculants in germination and pot trial experiment. The isolates A5 and A6, identified as Pseudomonas plecoglossicida and Staphylococci saprophyticus through 16S rRNA gene sequencing, were found to be tolerant up to $700 \mathrm{mg} \mathrm{L}^{-1}$ of $\mathrm{Cr}$ (VI). Both were effective in solubilizing phosphate but only A5 (Pseudomonas plecoglossicida) was able to produce indole acetic acid. A5 also increased the percentage of seed germination from 17 to $46 \%$ and spinach plant's biomass by $44 \%$ with respect to the control. Keeping in view the results obtained, A5 (Pseudomonas plecoglossicida) appeared as the best species that was able to tolerate $\mathrm{Cr}$ stress and promote plant growth. Further, it can be developed as a bio-inoculant for non-food agricultural applications for remediation of $\mathrm{Cr}$ contaminated soils.
\end{abstract}

\section{Introduction}

Industrialization, agricultural practices and various anthropogenic activities lead to the build-up of heavy metals in the environment. These heavy metals pose serious threats to terrestrial and aquatic ecosystems. Chromium (Cr) is one of the seventeen chemicals that pose the highest danger to human health according to the United States Environmental Protection Agency (USEPA) [1]. It is a transition element which occurs naturally in rocks, plants, animals, soil, gases and in volcanic ash [2]. Chromium is one such toxic metal with regulatory limits set at $1.3 \mathrm{mg} \mathrm{kg}^{-1}$ in plants (WHO), $0.1 \mathrm{mg} \mathrm{L}^{-1}$ in water (WHO) and $100 \mathrm{mg} \mathrm{kg}^{-1}$ in soil $[3,4]$.

Chromium exists in the environment in several oxidation states of which the most stable and common are hexavalent and trivalent states which exhibit different properties. $\mathrm{Cr}$ (III) is considered to be a vital element, for glucose, lipid and protein metabolism in animals in small amounts whereas $\mathrm{Cr}(\mathrm{VI})$ is extremely toxic for biological systems [5]. It disseminates easily into soil and water as it is highly soluble, mobile and permeable through biological membranes [6].

$\mathrm{Cr}(\mathrm{VI})$ is usually present in the form of chromate $\left(\mathrm{CrO}^{-4}\right)$ and dichromate $\left(\mathrm{CrO}^{-7}\right)$, strong oxidizing agents, which get reduced from $\mathrm{Cr}(\mathrm{VI})$ to $\mathrm{Cr}(\mathrm{V})$ inside the cells leading to the formation of reactive oxygen species (ROS)
[7]. The effects of chromium exposure in plants include reduction in seed germination, root length, plant biomass and plant height [8]. Toxic level of $\mathrm{Cr}(\mathrm{VI})$ in plants also shows drastic effect on plant's dry matter and yield [9].

In this scenario, management and remediation of $\mathrm{Cr}$ contaminated soils is a challenge for all the stakeholders. Remediation through microorganisms, like bacteria, is a cost effective method and may be beneficial for plant growth [10]. Many microorganisms can accumulate or reduce certain heavy metals easily [11]. Microbes have a high surface area to volume ratio hence they provide a large area of contact to interact and react with the metals in their surroundings [12].

These microorganisms can further benefit the environment if they work simultaneously to improve other aspects under concern like improving plant growth. Thus, heavy metal-resistant plant growth-promoting bacteria are a novel and promising approach to solve the soil toxicity and food crop issues [10]. In this context, the specific objectives of the present study were i) Isolation and identification of $\mathrm{Cr}$ tolerant bacterial strains from contaminated soil, ii) Assessment of plant growth promoting potential of $\mathrm{Cr}(\mathrm{VI})$ tolerant species under controlled conditions.

\section{Materials and methods}

* Corresponding author: marshad@iese.nust.edu.pk 


\subsection{Soil sampling and characterization}

Four soil samples were obtained from pearl millet fields, in Gujrat $\left(32.57^{\circ} \mathrm{N}, 74.08^{\circ} \mathrm{E}\right)$, Pakistan, irrigated by wastewater from the industrial city. Soil was extracted in bulk amounts from $0-15 \mathrm{~cm}$ depth (upper surface) and from 15-30 $\mathrm{cm}$ depth (sub-surface). Physico-chemical parameters like electrical conductivity (EC) and $\mathrm{pH}$ were measured by adding soil to water in the ratio 1:5. The amount of hexavalent chromium $(\mathrm{Cr}(\mathrm{VI}))$ present was ascertained as per standard methods (APHA, 2012) using UV-Vis spectrophotometer (T-60U PG INSTRUMENTS UK) and soil sample with the highest chromium content was selected.

\subsection{Isolation and identification of bacteria from chromium-rich soil}

For the isolation and enumeration of bacteria, serial dilution technique was adopted [13]. One $\mathrm{mL}$ of each dilution was spread on nutrient agar plates followed by incubation at $37^{\circ} \mathrm{C}$ for 24 hours. After 24 hours, bacterial colonies were picked and cultures were purified by repeated streaking.

For their molecular characterization, the isolates were preserved in glycerol and sent to Genome Analysis Department Macrogen Inc., South Korea, for 16S rRNA gene sequencing. The sequences obtained were identified using BLAST search in the database of National Center for Biotechnology Information (NCBI). Phylogenetic analysis to check the relatedness of identified strains to existing ones was done using MEGA 7 software.

\subsection{Minimum inhibitory concentration of chromium}

The minimum inhibitory concentration (MIC) is the lowest concentration of $\mathrm{Cr}$ VI which inhibits growth of bacteria [14]. Nutrient agar plates, spiked with various concentrations of chromium $(0,100,150,200,250,300$, $350,500,600,700,800 \mathrm{mg} \mathrm{L}^{-1}$ ), were prepared and loops full of pure bacterial cultures were streaked on the prepared plates and were left to incubate at $37^{\circ} \mathrm{C}$ for 48 hours. Chromium tolerance was recorded based upon the growth of isolates in both types of media.

\subsection{In vitro screening of plant growth-promoting (PGP) activity of Cr-tolerant isolates}

\subsubsection{Indole acetic acid (IAA) production}

Indole acetic acid is a plant growth stimulating hormone. To check IAA production by the bacterial isolates, they were cultured on Luria Broth medium containing tryptophan. The inoculated media was incubated at $37^{\circ} \mathrm{C}$ for 24 hours. After the incubation period the culture broth tubes were centrifuged at 2,000 rpm for $20 \mathrm{~min}$ and $1 \mathrm{~mL}$ of the supernatants were transferred to empty sterile test tubes. One drop of Orthophosphoric acid and $2 \mathrm{~mL}$ of freshly prepared Salkowski's reagent $(50 \mathrm{~mL} ; 49 \mathrm{~mL}$, $35 \% \mathrm{HClO}_{4}+1 \mathrm{~mL}, 0.5 \mathrm{M} \mathrm{FeCl}_{3}$ ) was added to the tubes.
The tubes were left to incubate for 30 minutes [15]. The development of a pink color confirmed IAA production by the isolate.

\subsubsection{Phosphate solubilizing activity}

Chromium tolerant bacteria were tested for their phosphate solubilizing ability; a plant growth enhancing trait, by disc diffusion assay described by Gupta et al. [16]. Inorganic phosphate, calcium phosphate $\left[\mathrm{Ca}_{3}(\mathrm{PO} 4)_{2}\right]$, was added to nutrient agar medium and each isolate was streaked in the center of the plates and left to incubate at $37^{\circ} \mathrm{C}$ for 5 days. The zone of clearing around the colony confirmed phosphate solubilizing ability. The larger the diameter of the halo, the better was the solubilizing activity.

\subsubsection{Pot trial experiment for spinach seedlings}

Clayey loam soil in bulk quantity was dried, crushed in a ball mill and sieved using a $2 \mathrm{~mm}$-mesh. The prepared soil was spiked with $\mathrm{Cr}$ (VI) salt $\left(100,200,300,400 \mathrm{mg} \mathrm{kg}^{-1}\right)$ and one set was fixed as control. Three week old spinach seedlings were obtained from a local plant nursery. These were carefully transplanted into the spiked soil. Organic compost and PGPB isolates, A5 and A6 (at $0.5 \mathrm{OD}_{600}$ ), were added to each of the five replicates of the four $\mathrm{Cr}(\mathrm{VI})$ treatments and the control. Spinach plants were provided the required cool temperature, constant watering and mulching for two weeks after which they were harvested and their physical parameters were recorded.

\subsection{Statistical Analysis}

Data of each treatment, was subjected to single factor and two-way analysis of variance (ANOVA). The means and standard deviations for all parameters were also calculated.

\section{Results and Discussion}

Equations should be centred and should be numbered with the number on the right-hand side.

\subsection{Physico-chemical analyses of soil}

The $\mathrm{pH}$, electrical conductivity (EC) and the chromium composition of the four soil samples were tested. The $\mathrm{pH}$ of the soils fell in the same slightly acidic to neutral range i.e. $6.86,6.85,6.50$ and 6.77 for the samples S1, S2, B1 and $\mathrm{B} 2$, respectively. $\mathrm{EC}$, which is a measure of the amount of salts present, varied considerably due to differences in inherent factors like soil mineral composition and texture etc. The EC of S1, S2, B1 and B2 was recorded as $56.3,163.1,256$ and $550 \mu \mathrm{S} \mathrm{cm}^{-1}$ respectively. Analysis for hexavalent chromium via UVVis spectrophotometer revealed that the amount of $\mathrm{Cr}(\mathrm{VI})$ in $\mathrm{B} 2$ was the highest i.e. $177 \mathrm{mg} \mathrm{kg}^{-1}$. This amount is higher than the permissible limit for $\mathrm{Cr}(\mathrm{VI})$ in soil, 100 
$\mathrm{mg} \mathrm{kg}{ }^{-1}$, according to Dutch Standards [4]. B2 sample, being chromium-rich, was appropriate for the isolation of chromium tolerant bacteria.

\subsection{Identification and PGP activity of bacterial isolates}

Bacterial colonies were isolated from soil sample B through the serial dilution method. Six isolates were able to solubilize inorganic phosphate to varying degrees however, only one tested positive for IAA production. Table 1 shows the results of all the tests conducted.

Table 2. Accession numbers and Plant Growth Promoting (PGP) characteristics of bacterial isolates.

\begin{tabular}{cccc}
\hline $\begin{array}{c}\text { Strain } \\
\text { ID }\end{array}$ & $\begin{array}{c}\text { Accession } \\
\text { numbers }\end{array}$ & $\begin{array}{c}\text { IAA } \\
\text { production }\end{array}$ & $\begin{array}{c}\text { P } \\
\text { solubilization }\end{array}$ \\
\hline A2 & KX262672 & - & + \\
A3 & KX262673 & - & - \\
A4 & KX262674 & - & + \\
A5 & KX262675 & + & + \\
A6 & KX262676 & - & + \\
A7 & KX262677 & - & - \\
A8 & KX262678 & - & - \\
A9 & KX262679 & - & - \\
A10 & KX262680 & - & + \\
A11 & KX262681 & - & - \\
A13 & KX262682 & - & + \\
\hline
\end{tabular}

The 11 isolates were characterized at molecular level and the predominant species were identified as Bacillus sp. (A2), Staphylococcus haemolyticus (A3), Bacillus cereus (A4), Pseudomonas plecoglossicida (A5), Staphylococcus saprophyticus (A6), Bacillus stratosphericus (A7), Staphylococcus aureus (A8, A9, A11), Bacillus aryabhattai (A10) and Agrobacterium tumefaciens (A13).

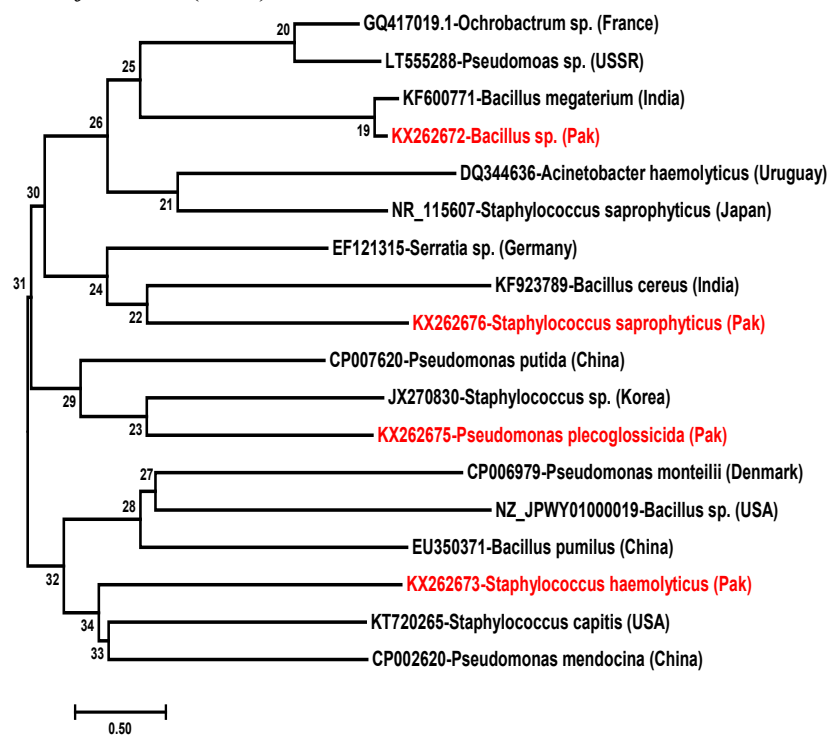

Fig. 1. Below the figure. Phylogenetic neighbor-joining tree of isolates created with MEGA 7 software.
The sequences obtained from 16S rRNA gene sequencing were submitted to GenBank under accession numbers listed in Table 1 and a phylogenetic tree was constructed.

The tree (Figure 1) lists the four most tolerant strains isolated in this study and other related chromium-tolerant strains that have been quoted in literature [5,10,17]. Pseudomonas plecoglossicida (A5) and Staphylococcus haemolyticus (A3) are the species being first reported and identified as chromium-tolerant bacteria from Pakistan.

\subsection{Minimum inhibitory concentration (MIC) of chromium}

Table 2. Chromium tolerance of bacterial isolates against various $\mathrm{Cr}(\mathrm{VI})$ concentrations in nutrient agar plate method.

\begin{tabular}{ccccccccc}
\hline Strain & \multicolumn{7}{c}{ Chromium Concentrations $\left(\mathrm{mg} \mathrm{L}^{-1}\right)$} \\
ID & $\mathbf{2 0 0}$ & $\mathbf{2 5 0}$ & $\mathbf{3 0 0}$ & $\mathbf{3 5 0}$ & $\mathbf{5 0 0}$ & $\mathbf{6 0 0}$ & $\mathbf{7 0 0}$ & $\mathbf{8 0 0}$ \\
\hline A2 & +++ & +++ & +++ & ++ & - & - & - & - \\
A3 & +++ & +++ & +++ & ++ & - & - & - & - \\
A4 & +++ & +++ & ++ & - & - & - & - & - \\
A5 & +++ & +++ & +++ & +++ & +++ & ++ & + & - \\
A6 & +++ & +++ & +++ & +++ & +++ & ++ & + & - \\
A7 & +++ & +++ & ++ & - & - & - & - & - \\
A8 & $+++*$ & ++ & - & - & - & - & - & - \\
A9 & + & - & - & - & - & - & - & - \\
A10 & + & - & - & - & - & - & - & - \\
A11 & +++ & +++ & ++ & - & - & - & - & - \\
A13 & +++ & +++ & ++ & - & - & - & - & - \\
\hline
\end{tabular}

+++ maximum growth, ++ moderate growth, + less growth, no growth, *bacteria changes colour at specific comcentration

The eleven isolates were screened to check their $\mathrm{Cr}(\mathrm{VI})$ tolerance and were subjected to MIC assays. Strains A5 and A6, from the genus Pseudomonas and Staphylococcus respectively, were found to be tolerant of $\mathrm{Cr}$ (VI) up to concentration as high as $700 \mathrm{mgL}^{-1}$ (Table $2)$. The next group of tolerant strains, for concentration up to $350 \mathrm{mg} \mathrm{L}^{-1} \mathrm{Cr}(\mathrm{VI})$, were A2 and A3 from genus Bacillus and Staphylococcus respectively. It is well reported that Pseudomonas sp. was exhibit high tolerance to $\mathrm{Cr}(\mathrm{VI})$ and is highly effective in its reduction [18] as were Staphylococci sp. [19] and Bacillus sp. [11].

\subsection{IAA production and phosphate solubilization efficacy}

The eleven isolates were tested in vitro to determine their ability for production of Indole acetic acid and solubilize inorganic phosphate. Six out of eleven isolates (A2, A4, A5, A6, A10, and A13) tested positive for phosphate solubilization (Table 1) which included the $\mathrm{Cr}$ (VI) tolerant A2, A5 and A6. According to Freitas et al. [20], good phosphate solubilizers are known to produce a clearing zone of diameter more than $15 \mathrm{~mm}$ around their colonies. This was true for the isolates A1, A2, A5, A6, $\mathrm{A} 10$, and A13 which can be regarded as efficient phosphate solubilizers. On the other hand, only A5 out of the eleven tested positive for IAA production. Bacteria 
belonging to the genus Pseudomonas are known to produce IAA and that too higher than many other species [21]. The results showed that many heavy metal tolerant bacteria, like Pseudomonas sp. (A5), Bacillus sp. (A2) and Staphylococci sp. (A6) from this work, were also plant growth-promoting as reported earlier by Gadd [22].

\subsection{Effect of PGPB and $\mathrm{Cr}(\mathrm{VI})$ on spinach}

After 2 weeks growth in inoculated soil, the root and shoot lengths and wet and dry biomass of the spinach plants were recorded. The root and shoot length of the plants remained unaffected by the presence of PGP bacteria as shown by Figure 2. Root length increased by $1 \%$ with A5 and the shoot length decreased by $13 \%$ with respect to the control. In the presence of A6, the shoot length decreased by $1 \%$ and the root length increased by $20 \%$ with respect to the control but then showed inconsistent behaviour with increasing $\mathrm{Cr}(\mathrm{VI})$ concentrations. Sayel et al. [8] reported similar trend of decreasing root $(30,46$ and $66 \%$ decrease, respectively) and shoot (17, 20 and 55\% decrease, respectively) lengths of clover plants with the addition of 100, 200 and $300 \mathrm{mg}$ $\mathrm{L}^{-1} \mathrm{Cr}(\mathrm{VI})$. It was also reported in the same study that inoculation with Pseudomonas sp. enhanced the root and shoot lengths by 15 to $20 \%$ with respect to the control which was not observed in our study.

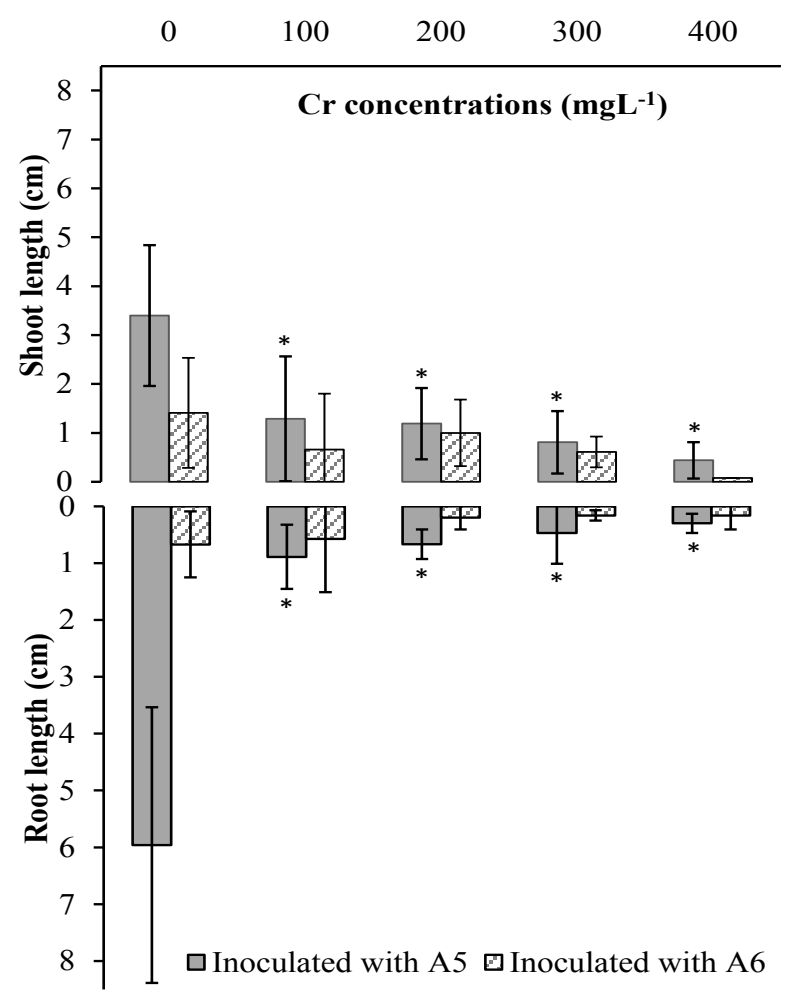

Fig. 2. Growth of spinach (root and shoot) with PGPB and various $\mathrm{Cr}$ treatments. Error bars represent standard deviations from using five replicates.

The addition of isolates A5 (Pseudomonas sp.) and A6 (Staphylococci sp.) brought about changes in the plant biomass. As shown in Figure 3, both the isolates were able to enhance biomass, A5 by $44 \%$ and A 6 by $7 \%$ with respect to the control, in the presence of $100 \mathrm{mg} \mathrm{kg}^{-1}$
$\mathrm{Cr}(\mathrm{VI})$. As the concentrations increased the biomass decreased significantly $(\mathrm{P}<0.05)$ with application of inoculants of both the isolates.

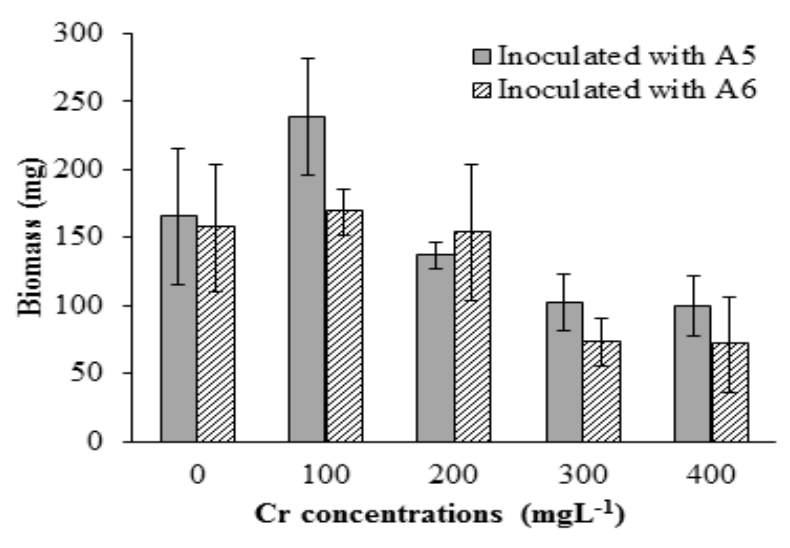

Fig. 2. Biomass (dry) of spinach seedlings with various $\mathrm{Cr}$ treatments. Error bars represent standard deviations from using five replicates (All at 5\% level of significance).

Application of bacterial inoculants to plants has been reported to not only improve plant growth but also enhance the yield of crops [23]. Another study in which the addition of PGP bacteria have been known to significantly increase fresh and dry weights of plants; maize seedlings, after 20 days of growth in chromium stressed soil [15] also supported the results obtained with spinach. These encouraging results have very high significance in management of heavy metal contaminated soils, particularly with $\mathrm{Cr}$. Beneficial traits can help to fight $\mathrm{Cr}$ toxicity to plants under stress conditions. Moreover, growth of non-food crops at $\mathrm{Cr}$ contaminated soils can help to produce biomass that can be further tested for biofuel production.

\section{Conclusions}

The study examined the capacity of 11 isolated bacterial species to tolerate and grow at various concentrations of chromium (VI). The screening process revealed that only Pseudomonas plecoglossicida and Staphylococcus saprophyticus were able to tolerate $\mathrm{Cr}$ (VI) presence up to $700 \mathrm{mg} \mathrm{L}^{-1}$. Staphylococcus saprophyticus solubilized Phosphate but was unable to produce IAA. Pseudomonas plecoglossicida utilized both these plant growth promoting mechanisms to enhance spinach plant's growth in $\mathrm{Cr}$ spiked soil. Inoculation of Pseudomonas plecoglossicida increased spinach plant's biomass by $44 \%$ with respect to the control. This reported capability of Pseudomonas plecoglossicida can help to develop inoculum to be used for remediation and management of Cr contaminated soils.

\section{References}

1. F. Kafilzadeh, S. Saberifard. Isolation and identification of chromium (VI)-resistant bacteria from Soltan Abad river sediments (Shiraz-Iran). Jundishapur. J. Health Sci. 8(1) (2016) 
2. N.T. Joutey, H. Sayel, W. Bahafid, N. El Ghachtouli. Mechanisms of hexavalent chromium resistance and removal by microorganisms. Rev. Environ. Contam. T. 233, 45-69 (2015)

3. WHO. Guidelines for Drinking-water Quality: Recommendations. World Health Organization. (2004)

4. D.E. Salt, M. Blaylock, N.P Kumar, V. Dushenkov V.B.D. Ensley, I. Chet, I. Raskin. Phytoremediation: a novel strategy for the removal of toxic metals from the environment using plants. 13(5), 468-474 (1995)

5. G. Suresh, N. Ravichandran, B. Ramesh, A. Suresh, G.V. Siva. Isolation and characterization of chromium-tolerant bacteria from chromiumcontaining waste water. Biorem. Biodiv. Bioavail. 5(1), 22-27 (2011)

6. A. Smrithi, K. Usha. Isolation and characterization of chromium removing bacteria from tannery effluent disposal site. Intl. J. Adv. Biotec. Res. 3(3), 644-652 (2012)

7. A.S.S. Ibrahim, M.A. El-Tayeb, Y.B. Elbadawi, A.A Al-Salamah. Isolation and characterization of novel potent $\mathrm{Cr}$ (VI) reducing alkaliphilic Amphibacillus sp. KSUCr3 from hypersaline soda lakes. Electron. J. Biotechnol. 14(4),4-18 (2011)

8. H. Sayel, N.T. Joutey, W. Bahafid, G.N. El. Chromium resistant bacteria: impact on plant growth in soil microcosm. Arch. Environ. Prot. 40(2), 81-89 (2014)

9. S. Khan, Q. Cao, Y.M. Zheng, Y.Z. Huang, Y.G. Zhu. Health risks of heavy metals in contaminated soils and food crops irrigated with wastewater in Beijing, China. Environ. Pollut. 152(3), 686-692 (2008)

10. M.U. Khan, A. Sessitsch, M. Harris, K. Fatima, A. Imran, M. Arslan, M. Afzal. Cr-resistant rhizo- and endophytic bacteria associated with Prosopis juliflora and their potential as phytoremediation enhancing agents in metal-degraded soils. Front. Plant Sci. (2015)

11. E. Ezaka, C.U. Anyanwu. Chromium (VI) tolerance of bacterial strains isolated from sewage oxidation ditch. Int. J. Environ. Sci. 1(7), 1725-1734 (2011)

12. A.I. Zouboulis, M.X. Loukidou, K.A. Matis. Biosorption of toxic metals from aqueous solutions by bacteria strains isolated from metal-polluted soils. Process. Biochem. 39(8), 909-916 (2004)

13. J.G. Holt. Bergey's Manual of Determinative Bacteriology, 9th edn. LWW, Baltimore, (1994)

14. J.G. Cappuccino, N. Sherman. Microbiology: A Laboratory Manual, 10th edn. Pearson, Boston, USA, (2013)

15. K.M. Lwin, M.M. Myint, T. Tar, W.Z.M. Aung. Isolation of plant hormone (Indole-3-Acetic Acid IAA) producing rhizobacteria and study on their effects on maize seedling. Eng. J. 16(5), 137-144 (2012)

16. S. Gupta, M.K. Meena, S. Datta. Isolation, characterization of plant growth promoting bacteria from the plant Chlorophytum borivilianum and invitro screening for activity of nitrogen fixation, phospthate solubilization and IAA production. Int. J. Curr. Microbiol. Appl. Sci. 3(7), 1082-1090 (2014)

17. C. Viti, A. Pace, L. Giovannetti. Characterization of $\mathrm{Cr}$ (VI)-resistant bacteria isolated from chromiumcontaminated soil by tannery activity. Curr. Microbiol. 46(1), 000-0005 (2003)

18. M.U. Rahman, S. Gul, M.Z.U. Haq. Reduction of chromium (VI) by locally isolated Pseudomonas sp. C-171. Turkish J. Biol. 31(3), 161-166 (2007)

19. C.G. Kouadjo, A. Zeze. Chromium tolerance and reduction potential of Staphylococci species isolated from a fly ash dumping site in South Africa. Afr. J. Biotechnol. (2011)

20. J.R. Freitas, M.R. Banerjee, J.J. Germida. Phosphatesolubilizing rhizobacteria enhance the growth and yield but not phosphorus uptake of canola (Brassica napus L.). Biol. Fert. Soils. 24(4), 358-364 (1997)

21. F. Ahmad, I. Ahmad, M.S. Khan. Screening of freeliving rhizospheric bacteria for their multiple plant growth promoting activities. Microbiol. Res. 163(2), 173-181 (2008)

22. G.M. Gadd. Heavy metal accumulation by bacteria and other microorganisms. Experientia. 46(8), 834840 (1990)

23. M.S. Mirza, W. Ahmad, F. Latif, J. Haurat, R. Bally, P. Normand, K.A. Malik. Isolation, partial characterization, and the effect of plant growthpromoting bacteria (PGPB) on micro-propagated sugarcane in vitro. Plant Soil. 237(1), 47-54 (2011) 